Jpn. J. Cancer Res. 90, 490-495, May 1999

\title{
Lung Cancer in Patients under 50 Years Old
}

\author{
Keigo Tominaga, ${ }^{1,3}$ Kiyoshi Mori, ${ }^{1}$ Kohei Yokoi, ${ }^{1}$ Munehide Noda, ${ }^{1}$ Naomi Goto, ${ }^{1}$ Suguru \\ Machida $^{1}$ and Masaki Nagai ${ }^{2}$ \\ ${ }^{1}$ Department of Thoracic Diseases, Tochigi Cancer Center, 4-9-13 Yohnan, Utsunomiya, Tochigi 320- \\ 0834 and ${ }^{2}$ Department of Public Health, Saitama Medical School, 38 Morohongo, Moroyama, Iruma- \\ gun, Saitama 350-0495
}

\begin{abstract}
A long-term retrospective study was carried out on 790 cases of lung cancer to determine if the clinicopathologic characteristics and survival rates of lung cancer patients under the age of 50 differ from those of patients 50 years of age or older at diagnosis by analyzing data on patients registered at Tochigi Cancer Center Hospital. Of the 790 patients, $77(9.7 \%)$ were under the age of 50 at diagnosis. The percentage of women in the younger patient group was significantly higher than that in the older patient group $(39.0 \%$ vs. $27.5 \% ; P=0.034)$. Tumor histology revealed a significant preponderance of adenocarcinomas (60 patients, $77.9 \%)$ and a paucity of squamous cell carcinomas $(8$ patients, $10.4 \%)$ in the younger age group $(P<0.001)$. The preponderance of adenocarcinoma was significant in both males and females (male: $P=0.004$, female: $P=0.004$ ). Smoking rates and rate of detection by cancer screening did not differ between the two age groups. Because of the paucity of smokers among the younger female patients, causes of lung cancer other than smoking should be sought in younger patients. No difference was found in the stage of the disease at presentation, treatment methods and survival rates between the two age groups. It is suggested that the prognosis for patients with lung cancer under the age of 50 is not significantly worse than for those aged 50 years or older, as has been shown by several investigators.
\end{abstract}

Key words: Lung cancer — Less than 50 years old - Clinicopathologic characteristics — Survival - Smoking history

Lung cancer is a common cause of cancer death and is a growing public health problem in Japan. ${ }^{1)}$ Most lung cancers occur in patients aged 60 years or older, and only $5-10 \%$ of all cases develop in patients younger than 50 years. $^{2-4)}$

There is controversy regarding the clinical features, pathologic findings, and outcome of lung cancer in young adults. Some investigators have found that adenocarcinoma is the most frequent histologic subtype in younger lung cancer patients, ${ }^{2,3,5-10)}$ whereas others have reported that squamous cell carcinoma is the most frequent subtype. ${ }^{3,11,12)}$ In addition, several reports have suggested a poor prognosis in younger patients with lung cancer, $3,8,9,13,14)$ whereas others have suggested that there is no significant difference in long-term survival between younger and older patients. ${ }^{3-5,10,11,15,16)}$ Possible causes for these conflicting results may include differences in the definition of younger patients, the stage of disease at presentation, treatments the patients received, and genetic and environmental differences (including the age at which smoking commenced $)^{2)}$ in the populations studied.

The present study was undertaken to determine if the clinicopathologic characteristics and/or survival rates of lung cancer patients younger than 50 years differ from

\footnotetext{
${ }^{3}$ To whom correspondence should be addressed.

E-mail address: ktominag@tcc.pref.tochigi.jp
}

those of patients aged 50 years or older at diagnosis by analyzing data on patients registered at our institution.

\section{MATERIALS AND METHODS}

The Tochigi Cancer Center Hospital tumor registry file, which includes records of all patients admitted to our center, was searched for records of lung cancer occurring in patients aged 50 years or younger for the years 1987 through 1996. The age used to separate younger from older patients was based on former studies ${ }^{2,17)}$ and on our intention to obtain information on patients with lung cancer who were in the prime of life, as well as younger patients. Our study was limited to patients with histologically confirmed cancer of the lung and did not include those with a diagnosis of bronchial carcinoid, adenoid cystic carcinoma, or carcinosarcoma. Furthermore, only patients with primary, untreated lung cancer were included; those with multiple cancers, regardless of the primary organ, were excluded. A comparison group consisted of patients meeting the same criteria except that they were aged 50 years or older at the time of diagnosis. Medical records of the patients were reviewed to obtain their history of cigarette smoking. Follow-up data were obtained on all patients up to June 30, 1998. The extent of disease was defined by imaging or other methods in the following categories: (1) local disease, neoplasm confined 
entirely to the organ of origin; (2) regional disease, extension beyond the organ of origin directly into surrounding tissues and/or into regional lymph nodes; and (3) distant disease, spread to parts of the body remote from the primary tumor by discontinuous metastasis. Duration of survival was defined as the time between the beginning of treatment and the date of death.

Comparisons between the two age groups in terms of gender, tumor histology, tumor stage and types of initial treatment were evaluated using the $\chi^{2}$ test. When a cell contained less than five, Fisher's exact method was employed. The relative survival rate was calculated using Ederer's method. ${ }^{18)}$ Survival rates were also calculated by the Kaplan-Meier method and compared by the log-rank test. The SAS statistical program (SAS Institute, Cary, $\mathrm{NC)}$ was used to calculate survival rates.

\section{RESULTS}

The clinicopathologic characteristics of 790 patients with primary lung cancer diagnosed between 1987 and 1996 who were registered at the Tochigi Cancer Center are listed in Table I. Seventy-seven patients $(9.7 \%)$ were younger than 50 years at the time of diagnosis, with a median age of 45 years. Among the 713 patients (90.3\%) who were aged 50 years or older at diagnosis, the median age was 67 years. Age distribution of the entire study population by decade revealed that only 14 patients (1.8\%; male: 8, female: 6 ) were younger than 40 years at diagnosis and that only one patient-a 15 -year-old girlwas younger than 30 years (Fig. 1).

The percentage of women in the younger patient group was significantly higher than that in the older patient group $(39.0 \%$ vs. $27.5 \%$; $P=0.034)$. Tumor histology revealed a significant preponderance of adenocarcinomas (60 patients, $77.9 \%$ ) and a paucity of squamous cell carcimomas (8 patients, 10.4\%) in the younger age group (Table I; $P<0.001$ ). The preponderance of adenocarcinoma was significant in both males and females (Table I; male: $P=0.004$, female: $P=0.004$ ). Although eight of 47 male patients younger than 50 years $(17.0 \%)$ had squamous cell carcinoma, no female patients in the same age group had that histologic subtype. In addition, only one patient under the age of 40-a 34-year-old man-had squamous cell carcinoma.

Patient staging at the time of diagnosis is shown in Table I. No significant differences were observed in the stages at the time of diagnosis between the younger and older groups.

The ratio of patients younger than 50 years remained stable at $9.1 \%$ between 1987 and 1990 and at $10.6 \%$ between 1993 and 1996. However, the percentage of women rose significantly from $24.6 \%$ between 1987 and 1990 to $32.1 \%$ between 1993 and $1996(P=0.043)$. In the entire patient cohort, 226 lung cancers $(28.6 \%)$ occurred in women.

Table II shows the initial treatment received by the patients in the study. Surgical resection was the initial treatment for $45.5 \%(35 / 77)$ of patients in the younger group and $44.6 \%$ (318/713) of those in the older group. Chemotherapy was the initial treatment for $42.9 \%$ (33/77) of patients in the younger group and 39.0\% (278/713) of those in the older group. Radiation therapy was given to $9.1 \%(7 / 77)$ of younger patients and to $12.5 \%$ (89/713) of older patients. Therefore, there were no significant differences in the initial methods of treatment between the younger and older patients $(P=0.737)$. Nor were significant differences observed between the two groups in

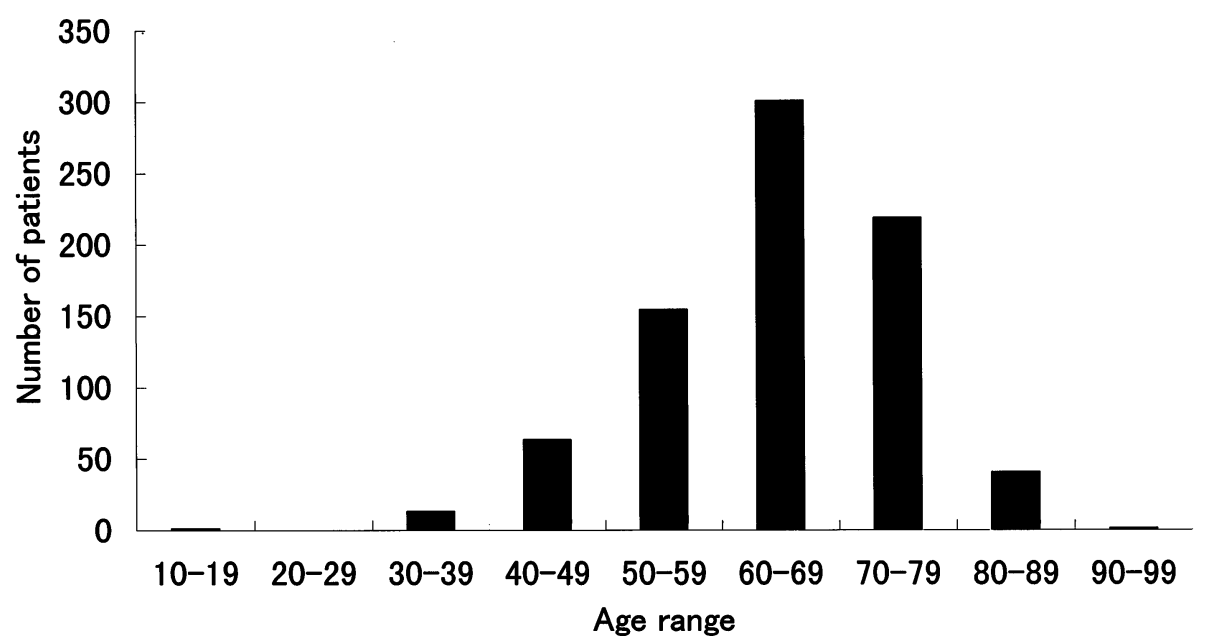

Fig. 1. Age distribution of 790 patients with lung cancer. Only 14 patients were under 40 years old at diagnosis. Lung cancer was rarely diagnosed before the age of 30 years. 
Table I. Clinicopathologic Characteristics

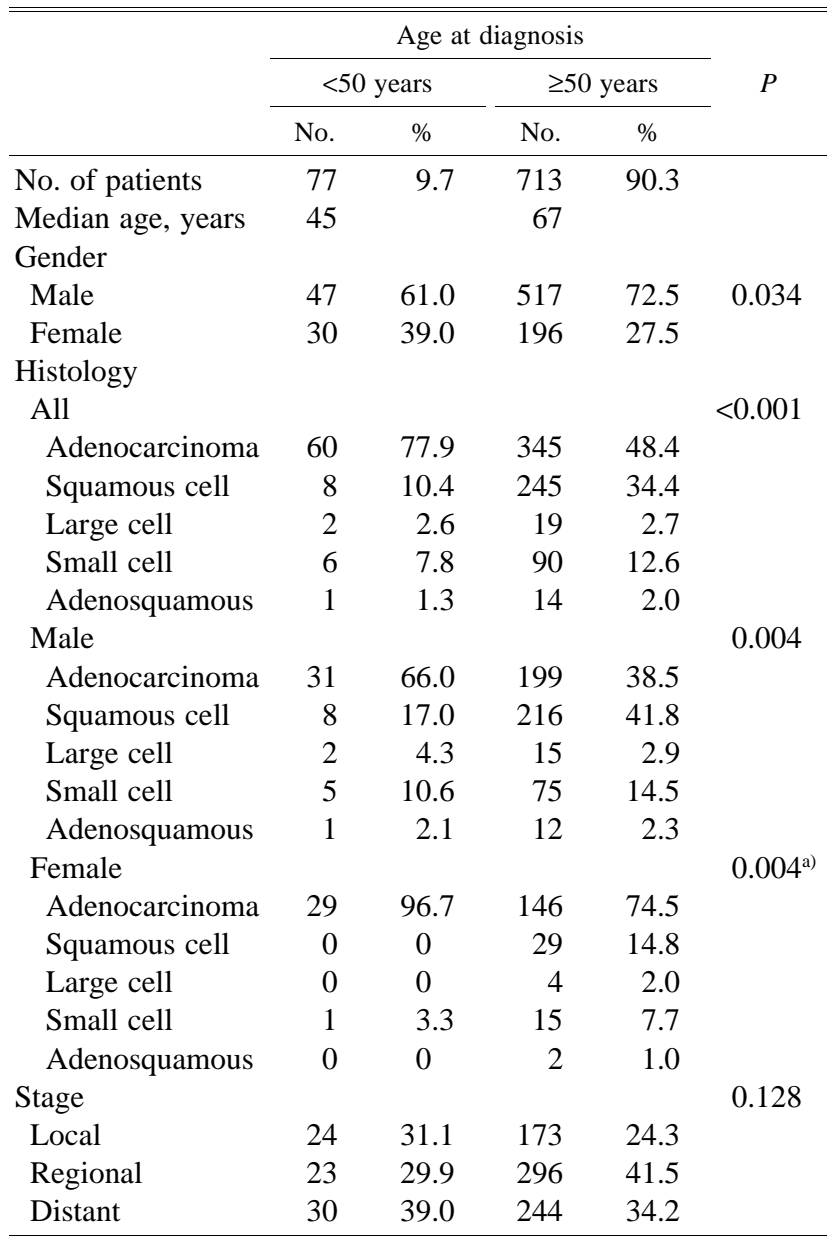

a) Calculated by summing the numbers of non-adenocarcinoma because the number of female patients under 50 years old was small or zero.

terms of the main treatment received $(P=0.554)$ (Table II). Thirty of the total of 790 patients received no therapy. Of those, 2 were in the younger age group and 28 were in the older age group, so there was no statistically significant difference between the two groups $(P=0.760)$. Therefore, younger and older patients were likely to have received similar cancer-directed treatment.

Relative survival rates for those who received any treatment, evaluated by life-table analysis methods, are shown in Table III. The 2-year relative survival rates were $41.3 \%$ and $41.8 \%$ in the younger and older groups, respectively; the 5-year relative survival rates were $33.0 \%$ and $31.1 \%$ in the younger and older groups, respectively. There was no statistically significant difference in survival rate between the younger and older patients (2-year survival rate: $P=0.936$; 5-year survival rate: $P=0.749$ ). Survival curves for both groups are shown in Fig. 2. There was
Table II. Initial and Main Therapy

\begin{tabular}{|c|c|c|c|c|c|}
\hline \multirow{3}{*}{ Treatment } & \multicolumn{4}{|c|}{ Age at diagnosis } & \multirow{3}{*}{$P$} \\
\hline & \multicolumn{2}{|c|}{$<50$ years } & \multicolumn{2}{|c|}{$\geq 50$ years } & \\
\hline & No. & $\%$ & No. & $\%$ & \\
\hline Initial treatment & & & & & 0.737 \\
\hline Surgery & 35 & 45.5 & 318 & 44.6 & \\
\hline Chemotherapy & 33 & 42.9 & 278 & 39.0 & \\
\hline Radiotherapy & 7 & 9.1 & 89 & 12.5 & \\
\hline None & 2 & 2.6 & 28 & 3.9 & \\
\hline Main treatment & & & & & 0.554 \\
\hline Surgery & 37 & 48.1 & 337 & 47.3 & \\
\hline Chemotherapy & 33 & 42.9 & 270 & 37.9 & \\
\hline Radiotherapy & 5 & 6.5 & 78 & 10.9 & \\
\hline None & 2 & 2.6 & 28 & 3.9 & \\
\hline
\end{tabular}

Table III. Relative Survival Rates at 2 and 5 Years

\begin{tabular}{cccc}
\hline \hline \multirow{2}{*}{ Year } & \multicolumn{2}{c}{ Age at diagnosis } & \multirow{2}{*}{$P$} \\
\cline { 2 - 3 } & \multicolumn{1}{c}{$<50$ years } & $\geq 50$ years & \\
\hline 2 & $0.413 \pm 0.057^{\text {a) }}$ & $0.418 \pm 0.019$ & 0.936 \\
5 & $0.330 \pm 0.057$ & $0.311 \pm 0.019$ & 0.749 \\
\hline
\end{tabular}

a) Value represents relative survival rate \pm SE.

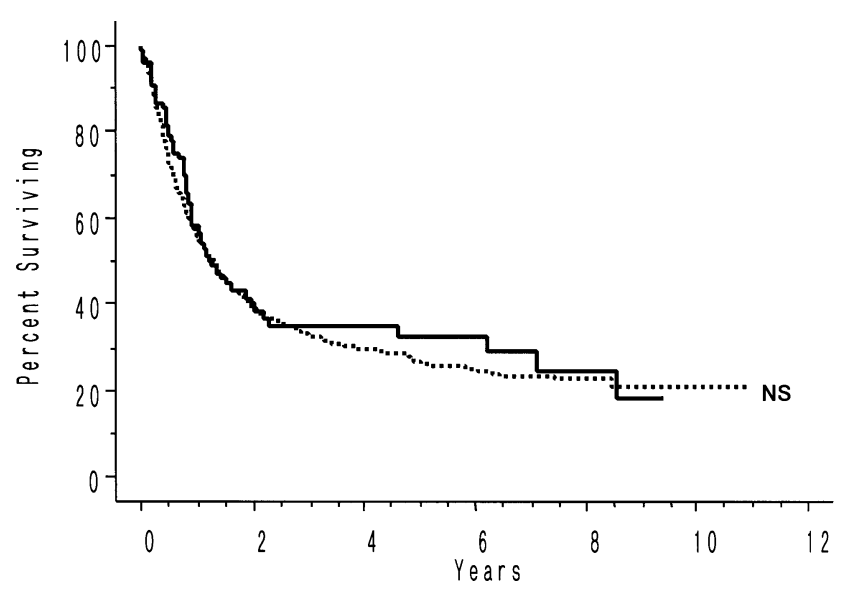

Fig. 2. Survival curves of patients who had cancer-directed treatments according to age group. $-<50$ years $(n=75) ; \cdots \cdots$. $\geq 50$ years $(n=685)$; NS, not significant.

also no significant difference between the survival curves of the two groups.

The numbers of cases detected by mass screening were investigated in our study population. Because people under the age of 40 are generally not referred for mass screening, 14 patients were excluded from the calculation. Five cancers among 63 patients aged between 40 and 50 years $(7.9 \%)$ and 57 cancers among 713 patients aged 
over 50 years $(8.0 \%)$ were detected by mass screening. There was no difference in detection rate between the two groups $(P=0.987)$.

Among 77 patients under age 50, 50 (64.9\%) were current smokers or ex-smokers, and among 713 patients aged 50 years or older, $502(70.4 \%)$ were current or ex-smokers (Table IV). The difference between the younger and

Table IV. Smoking History

\begin{tabular}{|c|c|c|c|c|}
\hline \multirow{3}{*}{ Sex } & \multirow{3}{*}{$\begin{array}{l}\text { Smoking } \\
\text { history }\end{array}$} & \multicolumn{2}{|c|}{ Age at diagnosis } & \multirow{3}{*}{$P$} \\
\hline & & $<50$ years & $\geq 50$ years & \\
\hline & & $\%$ & $\%$ & \\
\hline \multicolumn{5}{|c|}{ All (790 patients) } \\
\hline & Yes & 64.9 & 70.4 & 0.320 \\
\hline & No & 35.1 & 29.6 & \\
\hline \multicolumn{5}{|c|}{ Male (564 patients) } \\
\hline & Yes & 95.7 & 90.1 & 0.297 \\
\hline & No & 4.3 & 9.9 & \\
\hline \multicolumn{5}{|c|}{ Female (226 patients) } \\
\hline & Yes & 16.7 & 28.1 & 0.267 \\
\hline & No & 83.3 & 71.9 & \\
\hline
\end{tabular}

older groups was not statistically significant $(P=0.320)$. No gender-based difference in smoking history between the younger and older groups was observed (male: $P=$ 0.297, female: $P=0.267$ ). However, only 5 female patients $(16.7 \%)$ under the age of 50 were smokers. Median values of the Brinkman index (the number of cigarettes smoked daily $\times$ duration of smoking in years) were 590 and 1000 for the younger and older groups, respectively.

\section{DISCUSSION}

The prevalent view among oncologists is that young patients with lung cancer present with advanced disease and that their prognosis is worse than that of older patients. This view has been supported by several studies that revealed lower survival rates in younger patients. ${ }^{3,8,9,13,14)}$ However, other studies have demonstrated similar or better survival rates in younger patients than those of older patients..$^{3-5,10,11,15,16)}$ Table V, which includes only data from studies involving satisfactory numbers of subjects and/or that were statistically managed, shows that results of these studies have been biased by differences in the databases used and that some studies

Table V. Lung Cancer in Young Patients

\begin{tabular}{|c|c|c|c|c|c|}
\hline Source, year & $\begin{array}{l}\text { No. of } \\
\text { patients/ethnic } \\
\text { group }\end{array}$ & $\begin{array}{l}\text { Age of } \\
\text { population }\end{array}$ & $\begin{array}{l}\text { Database of } \\
\text { analysis }\end{array}$ & $\begin{array}{l}\text { Predominant } \\
\text { histology }\end{array}$ & $\begin{array}{l}\text { Survival advantage com- } \\
\text { pared with older patients }\end{array}$ \\
\hline Putnam, ${ }^{9)} 1977$ & $\begin{array}{c}\text { 24/USA } \\
\text { nothing else known }\end{array}$ & $<40$ & hospital records & adenocarcinoma & $\mathrm{NE}^{\mathrm{a})}$ \\
\hline DeCaro and Benfield, 5) 1982 & $\begin{array}{c}\text { 35/USA } \\
\text { nothing else known }\end{array}$ & $<40$ & hospital records & adenocarcinoma & no significant difference \\
\hline Pemberton et al., 1983 & $\begin{array}{c}113 / \text { USA } \\
\text { nothing else known }\end{array}$ & $<40$ & hospital records & adenocarcinoma & $\mathrm{NE}$ \\
\hline Icard et al., ${ }^{10)} 1992$ & 82/French & $<40$ & $\begin{array}{l}\text { hospital records } \\
\text { (surgically treated) }\end{array}$ & adenocarcinoma & no significant difference \\
\hline Shimono et al., ${ }^{16)} 1994$ & 24/Japanese & $<40$ & $\begin{array}{l}\text { hospital records } \\
\text { (surgically treated) }\end{array}$ & adenocarcinoma & no significant difference \\
\hline Sugio et al., ${ }^{15)} 1992$ & 22/Japanese & $\leq 40$ & $\begin{array}{l}\text { hospital records } \\
\text { (surgically treated) }\end{array}$ & no significant difference & no significant difference \\
\hline Green et al., ${ }^{8)} 1993$ & 48/Mexican & $\leq 40$ & hospital records & adenocarcinoma & poorer \\
\hline Roviaro et al.., ${ }^{11)} 1985$ & 155/Italian & $<45$ & hospital records & no significant difference & no significant difference \\
\hline Capewell et al., ${ }^{14)} 1992$ & 48/UK & $<45$ & tumor registry & small cell carcinoma & NE \\
\hline Bourke et al., ${ }^{3)} 1992$ & & $\leq 45$ & $\begin{array}{l}\text { population-based } \\
\text { tumor registry }\end{array}$ & & \\
\hline Chicago & 83 & & & adenocarcinoma & poorer \\
\hline Israel & 43 & & & adenocarcinoma & better \\
\hline Italy & 52 & & & squamous cell carcinoma & poorer \\
\hline McDuffie et al., ${ }^{2)} 1989$ & 187/Canadian & $\leq 50$ & $\begin{array}{l}\text { population-based } \\
\text { tumor registry }\end{array}$ & adenocarcinoma & NE \\
\hline Ramalingam et al.. ${ }^{17)} 1998$ & $\begin{array}{c}\text { 2804/USA } \\
\text { White: } 1999 \\
\text { Black: } 805\end{array}$ & $<50$ & $\begin{array}{l}\text { population-based } \\
\text { tumor registry }\end{array}$ & adenocarcinoma & better \\
\hline
\end{tabular}

a) Not evaluated. 
only evaluated patients who underwent surgical resection. ${ }^{10,15,16)}$ Moreover, the definition of young patients differed, with some investigators using 40 years and others using 50 years as the cut-off age. Therefore, these results should be interpreted with caution.

In our study, based on a cancer registry in a cancer center, $9.7 \%$ of lung cancer patients were under the age of 50 at diagnosis, a value that agrees with the rate of occurrence cited in a study that analyzed a large communitybased cancer registry in the United States. ${ }^{17)}$ The youngest patient in our series was 15 years old, younger than a 19year-old patient reported previously. ${ }^{9)}$ Age distribution by decade of the study population under the age of 50 at the time of diagnosis showed that 63 of 77 patients $(81.8 \%)$ were between 40 and 49 years old, and that only 14 patients $(18.2 \%)$ were younger than 40 years. Moreover, lung cancer was rarely diagnosed before the age of 30 . Such a result is consistent with previous reports. ${ }^{11,17)}$

In the present study, the percentage of women in the younger patient group was significantly higher than that in the older group. This tendency is consistent with the findings of previous reports. ${ }^{2,5,13,15,17)}$ Using a large community-based cancer registry and the same age definition as our study, Ramalingam et al. ${ }^{17)}$ have also demonstrated an overrepresentation of younger female patients with lung cancer. In addition, the present study revealed that adenocarcinoma was the most frequent histologic subtype in younger patients with lung cancer, which is consistent with the findings in American and Japanese studies. ${ }^{2,3,5-10)}$ For example, in a hospital-based study, Tsugane et al. ${ }^{7)}$ have shown that the most frequent histologic type was adenocarcinoma in both male and female patients between the ages of 30 and 49 . However, squamous cell carcinoma is the most frequent subtype in both younger and older lung cancer patients in Europe. ${ }^{3,12)}$ The incidence of various histologic subtypes might depend on the age at which smoking commenced, ${ }^{2)}$ as well as genetic differences among ethnic groups. These differences may make meaningful comparison difficult. Previous reports have noted that smoking was an important factor in the occurrence of lung cancer in young people ${ }^{2,5,11,12-14)}$ and the reason for the relative increase in the number of women among the young patients is the increased incidence of smoking among women. ${ }^{3,13,17,19)}$ In the present study, the ratio of smokers was not significantly different between the two age groups, even when males and females were considered separately. In addition, the histological subtypes that have been suggested to have a close association with smoking are squamous cell carcinoma and small cell carcinoma, not adenocarcinoma. ${ }^{20,21)}$ Moreover, the number of younger female smokers (5 out of 30 patients) in this study was small. Therefore, the cause of the striking predominance of adenocarcinoma in female patients younger than 50 years could not be attributed to smoking alone.
Investigators have cited passive inhalation of tobacco smoke, ${ }^{22,23)}$ occupational exposure to hazardous substances, ${ }^{8}{ }^{84)}$ family history, ${ }^{25)}$ past history of pneumonia ${ }^{26)}$ and indoor air pollution ${ }^{27}$ as factors other than smoking relevant to the etiology of lung cancer. Using results from an analytical study of data from the Surveillance, Epidemiology, and End Results Program of the National Cancer Institute, Dodds et al. ${ }^{28)}$ have reported that both overall and for each sex, the incidence of adenocarcinoma has increased significantly since 1974 . It was especially higher among females than among males, and the researchers suggested that a factor or a combination of factors other than cigarette smoking may be etiologically related to adenocarcinoma. Although smoking is an important cause of lung cancer, other exogenous as well as endogenous factors, and especially female factors in women, ${ }^{29)}$ may contribute to the development of primary lung cancer. These possibilities deserve further exploration..$^{8,30)}$

Previous studies have reported that fewer young patients present with early-stage disease., $3,6,8,9,13,15-17)$ However, our study revealed that $31.1 \%$ of lung cancer patients younger than 50 years presented with local-stage disease, and a similar percentage of older patients presented with the same stage. As a whole, there was no significant difference between the younger and older patient groups in the stage at which patients presented. In Japan, lung cancer screening has been conducted among the population over the age of 40 . Five of the 77 patients who were under the age of 50 were detected by the procedure. Of these, 3 patients had local and 2 had regional diseases. Therefore, in contrast to previous reports, ${ }^{6,31)}$ lung cancer screening has the potential to detect young patients with lung cancer in an earlier stage in Japan.

In our study the main treatment conducted for about half of both age groups was surgery. In addition, chemotherapy and radiotherapy were also performed with similar frequency for both groups. This means that both groups received similar treatment, and yet, survival rates were not significantly different between the groups. These results are similar to those in the report by Ramalingam et $a l .,{ }^{17)}$ who found slightly better survival rates of patients under the age of 50 than those of older patients.

The present study confirmed the high frequency of women among patients under the age of 50 with lung cancer. Moreover, our findings corroborate previous indications that adenocarcinoma is more common among younger patients, and that the relative survival rates among younger and older patients are essentially the same. The present study suggests that lung cancer is not a more virulent disease in patients under the age of 50 as compared with those aged 50 or older, and that, in general, all patients with this disease might be treated according to the same therapeutic guidelines. 


\section{ACKNOWLEDGMENTS}

We thank Mrs. Yumiko Yagisawa and Miss Kayoko Otuka in our center for data collection. We are also very grateful to Dr. Wakako Ajiki in the Department of Cancer Control and Statistics at Osaka Medical Center for Cancer and Cardiovascular Dis-

\section{REFERENCES}

1) Kuroishi, T., Hirose, K., Tominaga, S., Ogawa, H. and Tajima, K. Prediction of future cancer mortality in Japan. Jpn. J. Clin. Oncol., 22, 365-369 (1992).

2) McDuffie, H. H., Klaassen, D. J. and Dosman, J. A. Characteristics of patients with primary lung cancer diagnosed at age 50 years or younger. Chest, 96, 1298-1301 (1989).

3) Bourke, W., Milstein, D., Guira, R., Marco, D., Luisetti, M., Rubin, A. H. and Smith, L. J. Lung cancer in young adults. Chest, 102, 1723-1729 (1992).

4) Kyriakos, M. and Webber, B. Cancer of the lung in young men. J. Thorac. Cardiovasc. Surg., 67, 634-648 (1974).

5) DeCaro, L. and Benfield, J. R. Lung cancer in young persons. J. Thorac. Cardiovasc. Surg., 83, 372-376 (1982).

6) Pemberton, J. H., Nagorney, D. M., Gilmore, J. C., Taylor, W. F. and Bernatz, P. E. Bronchogenic carcinoma in patients younger than 40 years. Ann. Thorac. Surg., 36, 509-513 (1983).

7) Tsugane, S., Watanabe, S., Sugimura, H., Arimoto, H., Shimosato, Y. and Suemasu, K. Smoking, occupation and family history in lung cancer patients under fifty years of age. Jpn. J. Clin. Oncol., 17, 309-317 (1987).

8) Green, L. S., Fortoul, T. I., Ponciano, G., Robles, C. and Rivero, O. Bronchogenic cancer in patients under 40 years old: the experience of a Latin American country. Chest, 104, 1477-1481 (1993).

9) Putnam, J. S. Lung carcinoma in young adults. JAMA, 238, 35-36 (1977).

10) Icard, P., Regnard, J. F., deNapoli, S., Rojas-Miranda, A., Dartevelle, P. and Levasseur, P. Primary lung cancer in young patients: a study of 82 surgically treated patients. Ann. Thorac. Surg., 54, 99-103 (1992).

11) Roviaro, G. C., Varoli, F., Zannini, P., Fascianella, A. and Pezzuoli, G. Lung cancer in the young. Chest, 87, 456459 (1985).

12) Seddon, D. J. and Partridge, M. R. Carcinoma of the bronchus in young adults. Br. J. Clin. Pract., 44, 24-25 (1990).

13) Antkowiak, J. G., Regal A.-M. and Takita, H. Bronchogenic carcinoma in patients under age 40. Ann. Thorac. Surg., 47, 391-393 (1989).

14) Capewell, S., Wathen, C. G., Sankaran, R. and Sudlow, M. F. Lung cancer in young patients. Respir. Med., 86, 499502 (1992)

15) Sugio, K., Ishida, T., Kaneko, S., Yokoyama, H. and Sugimachi, K. Surgically resected lung cancer in young adults. Ann. Thorac. Surg., 53, 127-131 (1992).

16) Shimono, T., Hayashi, T., Kimura, M., Yada, I., Namikawa, S., Yuasa, H. and Kusagawa, M. Surgical treatment of primary lung cancer in patients less 40 years of age. J. Clin. Oncol., 12, 981-985 (1994). eases for offering a data-analysis program and Dr. Naoyuki Okamoto in the Research Institute at Kanagawa Cancer Center for statistical advice.

(Received December 9, 1998/Revised February 10, 1999/ Accepted February 19, 1999)

17) Ramalingam, S., Pawlish, K., Gadgeel, S. and Kalemkerian, G. P. Lung cancer in young patients: analysis of a surveillance, epidemiology, and end results database. J. Clin. Oncol., 16, 651-657 (1998).

18) Ederer, F., Axtell, L. M. and Cutler, S. J. The relative survival rate: a statistical methodology. Natl. Cancer Inst. Monogr., 6, 101-121 (1961).

19) Zang, E. A. and Wynder, E. L. Difference in lung cancer risk between men and women: examination of the evidence. J. Natl. Cancer Inst., 88, 183-192 (1996).

20) Kreyberg, L. "Aetiology of Lung Cancer-A Morphological, Epidemiological and Experimental Analysis," pp. 17-26 (1969). Universitets Forlaget, Oslo.

21) Hirayama, T. The problem of smoking and lung cancer in Japan with special reference to the rising trend in age-specific mortality rate by number of cigarettes smoked daily. Jpn. J. Cancer Res. (Gann), 78, 203-210 (1987).

22) Trichopoulos, D., Kalandidi, A., Sparros, L. and MacMahon, B. Lung cancer and passive smoking. Int. J. Cancer, 27, 1-40 (1981).

23) Hirayama, T. Non-smoking wives of heavy smokers have a higher risk of lung cancer: a study from Japan. Br. Med. J., 282, 183-185 (1981).

24) Kabat, G. C. and Wynder, E. L. Lung cancer in nonsmokers. Cancer, 53, 1214-1221 (1984).

25) Tokuhata, G. K. and Lilienfeld, A. M. Familial aggregation of lung cancer in humans. J. Natl. Cancer Inst., 30, 289-312 (1963).

26) Wu, A. H., Henderson, B. E., Pike, M. C. and Yu, M. C. Smoking and other risk factors for lung cancer in women. J. Natl. Cancer Inst., 74, 747-751 (1986).

27) Wu, A. H., Dai, X. D., Blot, W., Xu, Z. Y., Sun, X. W., Xiao, H. P., Stone, B. J., Yu, S. F., Feng, Y. P., Ershow, A. G., Sun, J., Fraumeni, J. F., Jr. and Henderson, B. E. Lung cancer among women in north-east China. Br. J. Cancer, 62, 982-987 (1990).

28) Dodds, L., Davis, S. and Polissar, L. A population-based study of lung cancer incidence trends by histologic type. $J$. Natl. Cancer Inst., 76, 21-29 (1986).

29) Chaudhuri, P. K., Thomas, P. A., Walker, M. J., Briele, H. A., Das Gupta, T. K. and Beattie, C. W. Steroid receptors in human lung cancer cytosols. Cancer Lett., 16, 327-332 (1982).

30) McDuffie, H. H., Klaassen, D. J. and Dosman, J. A. Female-male differences in patients with primary lung cancer. Cancer, 59, 1825-1830 (1987).

31) Anderson, R. W. and Arentzen, C. E. Carcinoma of the lung. Surg. Clin. North Am., 60, 793-814 (1980). 